University of Wollongong

Research Online

Australian Institute for Innovative Materials -

Papers

Australian Institute for Innovative Materials

$1-1-2013$

\title{
Applications of voltammetric ion selective electrodes to complex matrices
}

Alexander R. Harris

Monash University, alexh@uow.edu.au

Jie Zhang

Monash University, jz248@uowmail.edu.au

Robert W. Cattrall

La Trobe University

Alan M. Bond

Monash University, alan.bond@monash.edu

Follow this and additional works at: https://ro.uow.edu.au/aiimpapers

Part of the Engineering Commons, and the Physical Sciences and Mathematics Commons

Research Online is the open access institutional repository for the University of Wollongong. For further information contact the UOW Library: research-pubs@uow.edu.au 


\title{
Applications of voltammetric ion selective electrodes to complex matrices
}

\begin{abstract}
The practical application of two different voltammetric ion selective electrodes (VISE) to measure ion activity in complex solutions has been explored. 7,7,8,8-tetracyanoquinodimethane (TCNQ) and tetrathiafulvalene (TTF) microcrystals adhered to an electrode surface act as a low selectivity voltammetric ion sensor. Resistance drop effects and $\mathrm{pH}$ artifacts were minimised by the addition of an "innocent" supporting electrolyte (buffer) to the analyte solution. In this format, addition of an ionophore to improve selectivity resulted in a reduction in current magnitude, due to competition for the ion. In contrast, voltammetry of a thin film containing a redox active species, electrolyte, ionophore and membrane solvent provides a highly selective ion sensor. Choice of ionophore was shown to affect the upper concentration detection limit. Use of ionic liquids as a combined membrane solvent and electrolyte was demonstrated. Methods to attach both VISE types to low-cost screen-printed electrodes have been explored. Various potential referencing techniques were also investigated. Both the microcrystal and thin film VISEs could be used to determine ion activity in complex solutions, as demonstrated in seawater, beverages, plasma and whole blood. Dissolved oxygen does not need to be removed, as it does not affect the response. However calibration methods are important for sensor accuracy and issues relating to electrode fouling must be addressed. 2013 The Royal Society of Chemistry.
\end{abstract}

\section{Keywords}

matrices, voltammetric, complex, applications, electrodes, selective, ion

\section{Disciplines}

Engineering | Physical Sciences and Mathematics

\section{Publication Details}

Harris, A. R., Zhang, J., Cattrall, R. W. \& Bond, A. M. (2013). Applications of voltammetric ion selective electrodes to complex matrices. Analytical Methods: advancing methods and applications, 5 (16), 3840-3852. 


\title{
Analytical Methods
}

\section{Applications of voltammetric ion selective electrodes to complex matrices $\uparrow$}

\author{
Alexander R. Harris,,$^{* a}$ Jie Zhang, ${ }^{a}$ Robert W. Cattrall ${ }^{b}$ and Alan M. Bond ${ }^{* a}$ \\ The practical application of two different voltammetric ion selective electrodes (VISE) to measure ion \\ activity in complex solutions has been explored. 7,7,8,8-tetracyanoquinodimethane (TCNQ) and \\ tetrathiafulvalene (TTF) microcrystals adhered to an electrode surface act as a low selectivity \\ voltammetric ion sensor. Resistance drop effects and $\mathrm{pH}$ artifacts were minimised by the addition of an \\ "innocent" supporting electrolyte (buffer) to the analyte solution. In this format, addition of an \\ ionophore to improve selectivity resulted in a reduction in current magnitude, due to competition for \\ the ion. In contrast, voltammetry of a thin film containing a redox active species, electrolyte, ionophore \\ and membrane solvent provides a highly selective ion sensor. Choice of ionophore was shown to affect \\ the upper concentration detection limit. Use of ionic liquids as a combined membrane solvent and \\ electrolyte was demonstrated. Methods to attach both VISE types to low-cost screen-printed electrodes \\ have been explored. Various potential referencing techniques were also investigated. Both the \\ microcrystal and thin film VISEs could be used to determine ion activity in complex solutions, as \\ demonstrated in seawater, beverages, plasma and whole blood. Dissolved oxygen does not need to be \\ removed, as it does not affect the response. However calibration methods are important for sensor \\ accuracy and issues relating to electrode fouling must be addressed.
}

Received 8th May 2013

Accepted 21st June 2013

DOI: 10.1039/c3ay40769a

www.rsc.org/methods diluted or modified in some way to remove or reduce the concentration of the specific interferents. Many analyses are now performed directly in the field, rather than after sample collection and transport back to a laboratory to reduce analysis time and cost, and to prevent sample contamination or degradation. Consequently, small, low-cost ion sensors that can be used in the field are now of significant interest. Sample dilution or modification with bulk solvent or chemicals is therefore not an option with these devices.

7,7,8,8-tetracyanoquinodimethane (TCNQ) and tetrathiafulvalene (TTF) have been used in a range of sensors. ${ }^{5-9} \mathrm{~A}$ voltammetric method for ion sensing based on microcrystals of TCNQ (or TTF) adhered to an electrode surface has been reported. ${ }^{\mathbf{1 0 - 1 3}}$ TCNQ (TTF) is reduced (oxidised) to TCNQ ${ }^{-}\left(\mathrm{TTF}^{+}\right)$ under conditions of cyclic voltammetry to form the monovalent species. In order to maintain charge neutrality, simultaneously with reduction (oxidation) involving transfer of electrons from (to) the electrode, counter ions in the solution must ingress into the microcrystals. The reverse process occurs when the potential direction is reversed. That is, oxidation of $\mathrm{TCNQ}^{-}$(reduction of $\mathrm{TTF}^{+}$) back to the neutral species requires the counter ions to be expelled from the crystals. The voltammetric response shows very sharp oxidation and reduction peaks with the mid-point potential $\left(E_{\mathrm{m}}\right)$ dependent on the counter-ion concentration according to eqn (1) and (2).

$$
E_{\mathrm{m}}=E^{0^{\prime}}+S \log \left[\mathrm{M}^{+}\right]
$$




$$
E_{\mathrm{m}}=E^{0^{\prime}}-S \log \left[\mathrm{X}^{-}\right]
$$

where $S$ is the sensitivity of the sensor and $E^{0^{\prime}}$ is a constant for a given system. The sensor is known to suffer from uncompensated resistance $\left(i R_{\mathrm{u}}\right)$ effects, with microelectrodes, RAM electrodes and dynamic $i R_{\mathrm{u}}$ compensation previously used to minimise this issue. ${ }^{11,12}$ In this paper, the inclusion of an innocent (in the redox and ion transfer senses) supporting electrolyte is used to reduce the $i R_{\mathrm{u}}$ drop and also act as a buffer.

The solid-state voltammetry with chemically modified TCNQ (and TTF) electrodes in contact with pure alkali cation (monovalent anion) electrolyte solutions is straightforward. The TCNQ sensor Nicolsky-Eisenman type of selectivity coefficients were found to be $K_{\mathrm{Rb}^{+}, \mathrm{Na}^{+}}=11.6>K_{\mathrm{Rb}^{+}, \mathrm{K}^{+}}=5.1>K_{\mathrm{K}^{+}, \mathrm{Na}^{+}}=2.3$, giving a selectivity of $\mathrm{Na}^{+}>\mathrm{K}^{+}>\mathrm{Rb}^{+}$. The TTF sensor had selectivity coefficients of $K_{\mathrm{Cl}^{-}, \mathrm{Br}^{-}}=66.7>K_{\mathrm{NO}_{3}^{-}, \mathrm{Br}^{-}}=12.6>K_{\mathrm{Cl}^{-}, \mathrm{NO}_{3}{ }^{-}}=5.3$, giving a selectivity of $\mathrm{Br}^{-}>\mathrm{NO}_{3}{ }^{-}>\mathrm{Cl}^{-}{ }^{-14}$ However, these selectivity coefficients are insufficient for most ion sensing environments, except when the ion of interest is in substantial excess.

A second class of surface confined voltammetric ion selective electrode (VISE) that has recently been developed ${ }^{15}$ possesses much higher selectivity coefficients that should be suitable for measuring ions of interest even in the presence of a large concentration of interfering ions. This VISE format consists of a membrane containing different combinations of an electroactive species, an ionophore and a supporting electrolyte dissolved in a membrane solvent. In this case, the reversible reduction or oxidation of the electroactive species requires ion transfer of a counter ion into the membrane solvent to maintain charge neutrality. The identity of the counter ion undergoing phase transfer is chiefly controlled by the ionophore present.

To date, both VISEs have been tested only in pure electrolyte solutions that have been purged by nitrogen. To demonstrate the potential capability of the sensors under conditions encountered outside of the laboratory, they must be tested in the presence of oxygen, applied to suitable but more complicated matrices such as found in seawater, plasma and whole blood and the bulky and expensive standard electrodes must be replaced with mass produced screen-printed versions. The work detailed in this paper explores these issues.

\section{Experimental section}

\section{Chemicals}

The electroactive species, 7,7,8,8-tetracyanoquinodimethane (TCNQ, 98\%) tetrathiafulvalene (TTF), 1,1'-ferrocenedicarboxylic acid, benzoquinone and hexamineruthenium(III) chloride; the ionophores, valinomycin, benzo-15-crown-5, bis[(benzo-15crown-4)-4'-ylmethyl]pimelate (K ionophore II), 2-dodecyl-2methyl-1,3-propanediyl-bis[ $N$-(5'-nitro(benzo-15-crown-5)-4'-yl)carbamate] (BME 44, K ionophore III), bis[(12-crown-4)methyl] dodecylmethylmalonate (Na ionophore VI), 4-tert-butylcalix[4]arene-tetraacetic acid tetraethylester ( $\mathrm{Na}$ ionophore $\mathrm{X}$ ), $N, N, N^{\prime}, N^{\prime}$-tetracyclohexyl-3-oxapentanediamide (ETH129, Ca ionophore II); the membrane solvent 2-nitrophenyl octyl ether (NPOE); high molecular weight poly(vinyl chloride) (PVC); the membrane supporting electrolyte tetraheptylammonium tetraphenylborate (THATPB) and aqueous supporting electrolytes 2-amino-2-(hydroxymethyl)-1,3-propanediol (TRIS), 4-(2-hydroxyethyl)piperazine-1-ethanesulfonic acid (HEPES) (all Sigma-Aldrich), KCl, $\mathrm{NaCl}, \mathrm{NaNO}_{3}, \mathrm{Na}_{2} \mathrm{SO}_{4}, \mathrm{KNO}_{3}, \mathrm{CaCl}_{2}$, $\mathrm{MgCl}_{2}, \mathrm{NaClO}_{4},\left(\mathrm{NH}_{4}\right)_{2} \mathrm{SO}_{4}, \mathrm{Na}_{2} \mathrm{HPO}_{4}, \mathrm{KH}_{2} \mathrm{PO}_{4}$ and $\mathrm{NH}_{4} \mathrm{Cl}$ (BDH, analytical grade purity) were used as received. Tetrahydrofuran (THF) analytical grade from BDH was distilled, as nondistilled or stabilized forms of THF may form peroxides that are able to react with TCNQ resulting in a brown solution that inhibits ISE function. The ionic liquids, 1-ethyl-3-methylimidazolium bis(trifluoromethane sulfonyl) amide (emim.tfsa) and $N$-butyl-methylpyrrolidinium bis(trifluoromethanesulfonyl) amide (P14.tfsa) were synthesized according to literature procedures $^{16,17}$ and trihexyl(tetradecyl)-phosphonium tris(pentafluoroethyl)trifluorophosphate (aph4.cph12) was a gift from Merck (Fig. S1 $\dagger$ ). Triply distilled water or water obtained from a MiniQ purification system (resistivity $\geq 18 \mathrm{M} \Omega \mathrm{cm}$ ) from Millipore Corp. was used to prepare aqueous electrolyte solutions. Dielectric ink was obtained from Ercon. Ethanol (BDH) was used as provided by the manufacturer. Nafion ( $5 \mathrm{wt} \%$, Sigma-Aldrich) was used in a 1 in 10 dilution in $50 \%$ ethanolwater, $10 \mu \mathrm{L}$ ( $1 \mu \mathrm{L}$ on screen printed electrodes) was drop cast onto the TCNQ modified electrode and dried using warm air from a hair drier. Albumin from bovine serum (BioReagent) and glycerol (both from Sigma-Aldrich) were used as received.

Sample solutions of a sports drink (Gatorade) and sea water were obtained locally. The milk sample was rehydrated from low heat skim milk powder (Food Sciences Australia) and cold water with $9 \%$ total solids at $\mathrm{pH}$ 6.7. Whole blood was collected at Oxford Biosensors in lithium heparin tubes (BD Vacutainer, 119 IU Heparin) or tubes without anticoagulant and spun down at $3800 \mathrm{rpm}$ for 20 minutes to separate out the plasma. Plasma was then frozen at $-39^{\circ} \mathrm{C}$ for storage and allowed to thaw for at least 30 minutes prior to testing. Delipidated serum (SIPAC batch S139 189-137) was also defrosted for at least 30 minutes before use.

\section{Instrumentation, electrodes and procedures}

Voltammetric experiments were undertaken in a conventional three-electrode cell with a BAS 100B (Bioanalytical Systems), or an Autolab PGSTAT100 (ECO-Chemie) electrochemical workstations or a home built potentiostat controlled by LabVIEW with automatic peak detection software. A 4-necked electrochemical cell that allowed reproducible positioning of the standard working, reference and auxiliary electrodes or a beaker when screen-printed electrodes were employed. When using macroelectrodes, the working electrodes were 1.5 or $3 \mathrm{~mm}$ diameter glassy carbon (GC) (IJ Cambria) or $3 \mathrm{~mm}$ edge plane graphite (EPG) polished with a $0.3 \mu \mathrm{m}$ alumina slurry on Microcloth polishing cloth and dried with tissue paper (Kimwipe). The reference electrode was a saturated calomel (SCE) for the microcrystal VISE, $\mathrm{Ag} / \mathrm{AgCl}(3 \mathrm{M} \mathrm{NaCl})$ for $\mathrm{K}^{+}$and $\mathrm{Ca}^{2+}$ or $\mathrm{Ag} / \mathrm{AgCl}(3 \mathrm{M} \mathrm{KCl})$ for $\mathrm{Na}^{+}$thin film VISE sensing experiments. For screen-printed electrode studies, conductive carbon ink working electrodes containing inbuilt $\mathrm{Ag} / \mathrm{AgCl}$ reference electrodes were used. ${ }^{18}$ The counter electrode was Pt mesh. 
TCNQ or TTF microcrystal modified electrodes were generally prepared by placing some crystals onto weighing paper and grinding them onto the electrode surface or using a mortar and pestle to grind crystals to various sizes before applying to the electrode surface with a tissue. These methods have been termed mechanical adhesion. The crystal sizes were in the micron scale but were not measured. Some electrodes were also modified by drop casting TCNQ or TTF dissolved in acetonitrile or acetone and allowing the solvent to evaporate, and despite the more uniform crystal morphology, no difference was seen in the voltammetric response. The usual degassing with solvent saturated nitrogen was eliminated in this work in order to simulate requirements of field-based applications of the ion sensor. The method used to prepare the thin film VISE modified GC electrode used for ion sensing is described in ref. 15 .

Results obtained with the microcrystal TCNQ sensor were compared with a commercial $\mathrm{Na}^{+}$(6.0508.100, Metrohm) membrane potentiometric ISE using a model $713 \mathrm{pH}$ meter (Metrohm) and $\mathrm{Ag} / \mathrm{AgCl}$ (saturated $\mathrm{KCl}$ ) reference electrode (607 Metrosensor, Metrohm). Results obtained from the microcrystal TTF sensor were compared with a spectrophotometric technique using flow injection analysis. The seawater was injected into the carrier stream containing mercury(II) thiocyanate $\left(\mathrm{Hg}(\mathrm{SCN})_{2}\right)$ and iron(III). Reaction of chloride with $\mathrm{Hg}(\mathrm{SCN})_{2}$ liberated $\mathrm{SCN}^{-}$, which combined with $\mathrm{Fe}(\mathrm{III})$ to form the complex ion $\mathrm{Fe}(\mathrm{SCN})_{2}{ }^{+}$, which is red in colour. The intensity of the coloured complex was measured spectrophotometrically at $470 \mathrm{~nm}$.

Results obtained with the thin film VISE were compared to the AEROSET 2 analyzer (Abbott) at the John Radcliffe Hospital, Oxford, UK, which performs over 50 different forms of chemical analyses, all by spectrophotometric techniques apart from $\mathrm{Na}^{+}$ and $\mathrm{K}^{+}$, which are by potentiometric ISE. The AEROSET 2 is able to perform 2000 tests per hour, or when running 6-7 tests per sample, over 200 samples per hour. It can be run 24 hours a day and allows a turnover of results of approximately one hour (mostly transport of sample to and from the doctor). The instrument was calibrated 6-7 times a day with a low and high calibrant solution. The software retains the previous 144 calibrations for statistical analysis (Table $\mathrm{S} 1 \dagger$ ). The $\mathrm{Na}^{+}$and $\mathrm{K}^{+}$activity, and total $\mathrm{Ca}^{2+}$ rather than $\mathrm{Ca}^{2+}$ activity are measured. A formula (eqn (3)) is typically used to determine the $\mathrm{Ca}^{2+}$ activity from the total $\mathrm{Ca}^{2+}$ concentration and the albumin concentration.

$$
\begin{aligned}
\text { Calcium activity }(\mathrm{mM})= & \text { total calcium }(\mathrm{mM}) \\
& +0.02\left(40-\operatorname{albumin}\left(\mathrm{g} \mathrm{L}^{-1}\right)\right)
\end{aligned}
$$

Typical ranges for $\mathrm{Na}^{+}, \mathrm{K}^{+}, \mathrm{Ca}^{2+}$ and $\mathrm{Cl}^{-}$concentrations are listed for blood (Table 1). There are a number of factors that can affect the response of an ISE in plasma. Hemodilution by more than $20 \%$ affects the ionic strength of the plasma and a suitable ionic strength "buffer" solution should be used. The addition of $\mathrm{Na}^{+}$heparin will increase the concentration of $\mathrm{Na}^{+}$in the sample. Heparinized plasma will cause the $\mathrm{K}^{+}$concentration to drop initially and then rise. Freezing or blood coagulation will cause the $\mathrm{K}^{+}$concentration to rise, and $\mathrm{Ca}^{2+}$ activity will drop after prolonged tourniquet application and exercise (due to binding by lactate), exposure to air (complexation with $\mathrm{CO}_{2}$ ), heparin exposure (1 IU of heparin will decrease $\mathrm{Ca}^{2+}$ activity by $0.01 \mathrm{mM}$ ) and freezing. Sample collection and treatment was designed to minimize these affects, for instance, using lithium heparin or no anti-coagulant, not diluting the plasma sample and spinning the blood sample down as soon as possible.

\section{Results and discussion}

\section{Modification of TCNQ and TTF microcrystal voltammetric ion selective electrodes for analysis of complex solutions}

When TCNQ or TTF mechanically adhered to an electrode surface, is placed in contact with $0.1 \mathrm{M} \mathrm{NaCl}_{(\mathrm{aq})}$, the first oneelectron reduction and oxidation processes of $\mathrm{TCNQ}_{(\mathrm{s})}$ and $\mathrm{TTF}_{(\mathrm{s})}$ respectively (Fig. 1 and eqn (4) and (5)) are well removed from either oxygen reduction or solvent Faradaic processes, allowing detection of the required $\mathrm{TCNQ}^{0 /-}$ and $\mathrm{TTF}^{\mathrm{O} /+}$ voltammetry, even in the presence of oxygen. For the TCNQ case, on the initial negative potential direction sweep when a $\mathrm{Na}^{+}$salt of TCNQ is produced on the electrode, a broad $\mathrm{TCNQ}^{\mathrm{O} /-}$ reduction process appears with a peak $\left(E_{\mathrm{p}}^{\mathrm{red}}\right)$ at $-0.079 \mathrm{~V}$. On the reverse direction of the potential sweep, current crossover occurs at $0 \mathrm{~V}$, indicative of a nucleation and growth process, prior to detection of a very sharp $\mathrm{TCNQ}^{-/ 0}$ oxidation peak $\left(E_{\mathrm{p}}^{\mathrm{ox}}\right)$ at $0.237 \mathrm{~V}$. The large reduction-oxidation peak potential separation arises from the solid-solid nucleation and growth process and is accompanied by crystal fragmentation and rearrangement during the initial cycles of potential. ${ }^{11,19,20}$ The oxidation process is clearly sharper than the reduction process, possibly due to the conductivity of NaTCNQ being higher than that of TCNQ. ${ }^{19,21,22}$ The magnitude of the peak separation also
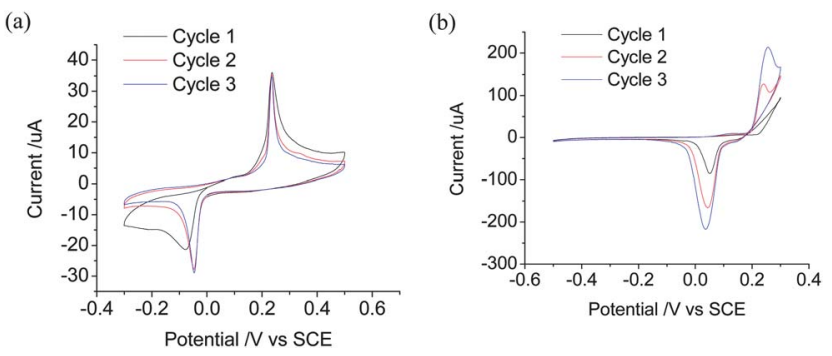

Fig. 1 Initial three cycles of potential at a scan rate of $100 \mathrm{mV} \mathrm{s}^{-1}$ when EPG electrodes containing mechanically adhered (a) TCNQ and (b) TTF are in contact with $0.1 \mathrm{M} \mathrm{NaCl}$ as the electrolyte.

Table 1 Typical composition of blood sample s1,52 $^{2}$

\begin{tabular}{llllr}
\hline Ion & $\mathrm{K}^{+}$ & $\mathrm{Na}^{+}$ & $\mathrm{Ca}^{2+}$ & $\mathrm{NH}_{4}^{+}$ \\
\hline Concentration & $3.6-5.0 \mathrm{mM}$ & $135-145 \mathrm{mM}$ & $2.25-2.88 \mathrm{mM}$ & $2.22-6.93 \mu \mathrm{M}$
\end{tabular}


may be related to the $\left[\mathrm{M}^{+} \mathrm{TCNQ}^{-}\right]$and TCNQ conductivity. On the second and subsequent cycles of the potential, both the reduction and oxidation processes become narrower (have a smaller peak width at half height) which is most likely due to the formation of a more uniform chemically modified surface. However, the charge associated with both processes diminishes as some $\left[\mathrm{Na}^{+} \mathrm{TCNQ}^{-}\right]$dissolves into the bulk solution. To improve the sensor stability, a polymer coating permeable to the analyte can be applied over the electrode and crystals. ${ }^{19}$ In the present case, the TCNQ sensor surface was coated with polymer by evaporation of $10 \mu \mathrm{L}$ of diluted Nafion (a negatively charged perfluorosulfonated cation-exchange polymer), which allowed cations to pass through, but not $\mathrm{TCNQ}^{-}$. This minimised the dissolution of the reduced $\mathrm{TCNQ}^{-}$, resulting in longer lifetimes with larger peak currents.

$$
\begin{gathered}
\mathrm{TCNQ}_{(\mathrm{s})}+\mathrm{Na}^{+}{ }_{(\mathrm{aq})}+\mathrm{e}^{-} \rightleftharpoons\left[\mathrm{Na}^{+} \mathrm{TCNQ}^{-}\right]_{(\mathrm{s})} \\
\mathrm{TTF}_{(\mathrm{s})}+\mathrm{Cl}^{-}{ }_{(\mathrm{aq})} \rightleftharpoons\left[\mathrm{TTF}^{+} \mathrm{Cl}^{-}\right]_{(\mathrm{s})}+\mathrm{e}^{-}
\end{gathered}
$$

TTF voltammetry also in contact with $\mathrm{NaCl}$ electrolyte (Fig. 1b) is analogous to that of TCNQ, but rather than the $\mathrm{Na}^{+}$ cation counter-ion being intercalated, the $\mathrm{Cl}^{-}$anion is incorporated into the crystal. The peak current associated with the $\mathrm{TTF}^{0 /+}$ oxidation and $\mathrm{TTF}^{+/ 0}$ reduction processes are significantly larger than the TCNQ process, leading to an enhanced level of $i R_{\mathrm{u}}$ drop, which may be a consequence of the higher conductivity of $\left[\mathrm{TTF}^{+} \mathrm{Cl}^{-}\right]$relative to that of $\left[\mathrm{Na}^{+} \mathrm{TCNQ}^{-}\right]^{23}$ or simply, more compound may be present on the electrode surface as the TTF crystals are harder, making attachment of small crystals difficult. ${ }^{10}$ In an effort to introduce an analogous coating protocol used with the microcrystal TCNQ sensor, polyethylene imine was used as a positively charged polymer for coating the TTF modified electrode. Unfortunately, this polymer dissolved too rapidly into the aqueous solution to be useful.

TCNQ and TTF are also able to undergo a second electron transfer step, when $0.1 \mathrm{M} \mathrm{NaCl}$ is the electrolyte, to form a divalent species. However, these more highly charged $\left[\mathrm{Na}_{2}^{+} \mathrm{TCNQ}^{2-}\right]$ and $\left[\mathrm{TTF}^{2+} \mathrm{Cl}^{-}{ }_{2}\right]$ species are moderately water soluble, resulting in rapid loss of solid from the electrode surface and the voltammetric peaks are broader. Thus, the $\mathrm{TCNQ}^{-/ 2-}$ and $\mathrm{TTF}^{+/ 2+}$ processes are not analytically useful.

A large peak current with a small peak width at half height is obtained at salt concentrations above $100 \mathrm{mM}$. In contrast, at $\leq 10 \mathrm{mM}$ salt concentrations for both the TCNQ and TTF sensors, $i R_{\mathrm{u}}$ drop leads to broadening of the voltammetric peaks (Fig. 2a and e).

In order to reduce the peak broadening associated with $i R_{\mathrm{u}}$ drop, particularly at low salt concentrations, carbon fibre random array microelectrodes (RAM) or dynamic $i R_{\mathrm{u}}$ compensation were introduced. ${ }^{11,14,19}$ However, these techniques are too expensive or not practical for routine field-based applications. Consequently, the possibility of adding an inert (i.e. nonsensing) supporting electrolyte to reduce the solution resistance was undertaken. Clearly, the supporting electrolyte must not be intercalated into the TCNQ or TTF crystals during the course of
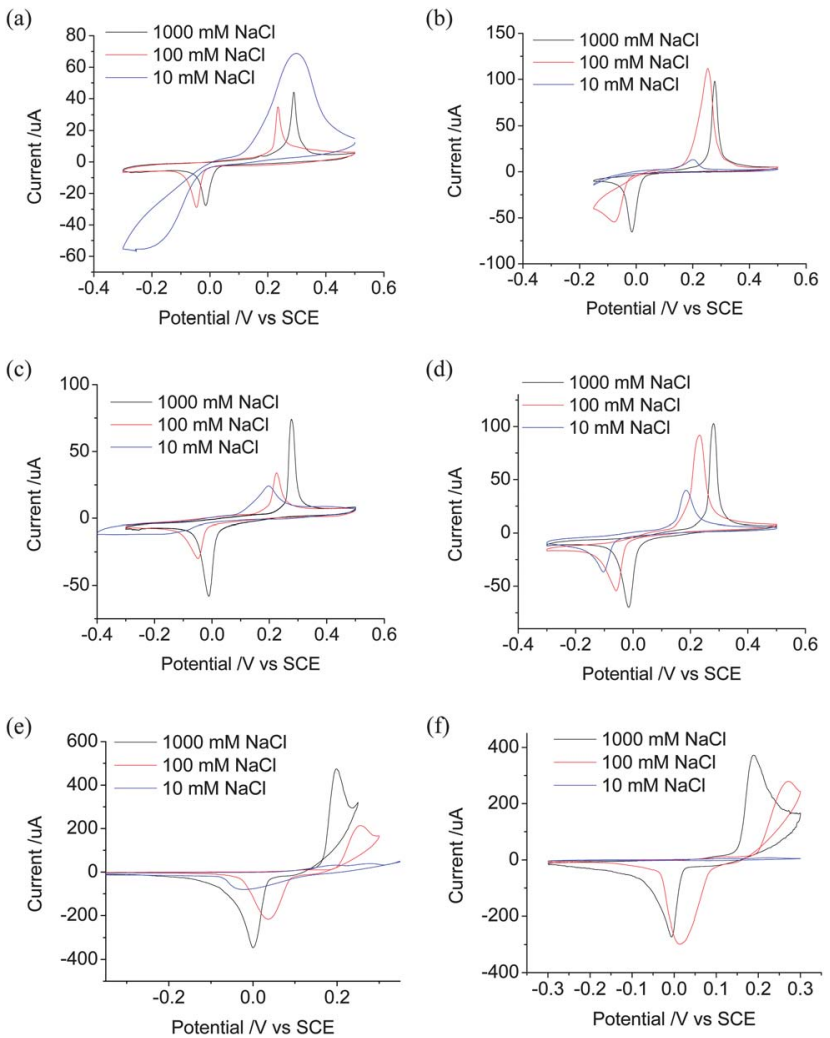

Fig. 2 Cyclic voltammetry at designated $\mathrm{NaCl}$ concentrations at a scan rate of $100 \mathrm{mV} \mathrm{s}^{-1}$ with an EPG electrode containing mechanically adhered (a-d) TCNQ and (e and f) TTF. (a) 3rd cycle of potential, (b) 3rd cycle of potential with $50 \mathrm{mM}$ TRIS and HEPES present as an "innocent electrolyte", (c) 10th cycle of potential with Nafion coating, (d) 10th cycle of potential with Nafion coating and $50 \mathrm{mM}$ TRIS and HEPES, (e) 3rd potential cycle and (f) 3rd potential cycle with 50 mM TRIS and HEPES present as an "innocent electrolyte".

the voltammetry, as this would interfere with the ion sensing. Large bulky ions of TRIS and HEPES buffers were examined. At a $50 \mathrm{mM}$ : $50 \mathrm{mM}$ TRIS : HEPES ratio, the electrolyte solution has a $\mathrm{pH}$ of 7.5, thus the added "innocent electrolyte" acts as a supporting electrolyte, as well as a buffer, which also aids in ion sensing of solutions having variable $\mathrm{pH}$. In the presence of this "innocent electrolyte" the reduced $i R_{\mathrm{u}}$ drop resulted in a marginal improvement with a better defined baseline, and higher stability of the peak potentials and current magnitude (Fig. 2b and f). Simply coating the TCNQ modified electrode with Nafion did not drastically improve the response at low $\mathrm{NaCl}$ salt concentrations (Fig. 2c). However, when supporting electrolyte and Nafion were used in combination, well defined peaks are obtained, even with dilute $\mathrm{NaCl}$ concentrations (Fig. 2d). A similar improvement of the TTF voltammetry is expected if a suitable polymer coating could be found.

The average of the oxidation and reduction peak potentials $\left(E_{\mathrm{m}}\right)$ obtained on the tenth cycle is recommended for sensing purposes and varies with the counter-ion concentration. Using the tenth cycle ensures the crystal fragmentation process is no longer significant and that there are smaller peak widths at half height, increasing the peak potential and subsequent sensor measurement precision. With a scan rate of $100 \mathrm{mV} \mathrm{s}^{-1}$, this allows measurement in $160 \mathrm{~s}$. Faster scan rates increase the 
sensor current, and hence the $i R_{\mathrm{u}}$ drop and peak width, reducing the sensor precision. Slower scan rates may enhance the precision but can lead to increased dissolution of $\mathrm{TCNQ}^{-}$ and $\mathrm{TTF}^{+}$and will increase the measurement time, which is undesirable for point of care devices. Consistent with previous work, ${ }^{10,12}$ variation of the sodium and chloride concentrations shifted the $E_{\mathrm{m}}$ value of the TCNQ ${ }^{0 /-}$ voltammetry by $46 \mathrm{mV}$ (Fig. S2 $\dagger$ ) and the $\mathrm{TTF}^{0 /+}$ voltammetry by $53 \mathrm{mV}$ per decade of concentration $\left(\mathrm{Na}^{+}\right.$and $\mathrm{Cl}^{-}$respectively) change versus a SCE or $\mathrm{Ag} / \mathrm{AgCl}$ reference electrode that is separated from the test solution by a salt bridge. Initially, Nernstian sensitivity was reported, ${ }^{19}$ but subsequently a sub-Nernstian response has been obtained, in this and other studies. ${ }^{12,13}$ The origin of this difference is not understood. Importantly, neither the presence of oxygen nor variation in crystal size affects sensor sensitivity.

There is an inherent selectivity in the TCNQ and TTF voltammetry. However, the selectivities are insufficient for many applications. Ionophores are compounds that bind specific ions and are typically used in ISEs. Crown ethers are well known to be strong binders of cations with 15-crown-5 having a high selectivity for $\mathrm{Na}^{+}$and 18-crown-6 for $\mathrm{K}^{+}$. Crystal structures of crown ether- $\left[\mathrm{M}^{+} \mathrm{TCNQ}^{-}\right]$salts have been reported, ${ }^{24}$ although they showed a significantly lower conductivity than the pure $\left[\mathrm{M}^{+} \mathrm{TCNQ}^{-}\right]$salts. Benzo-15-crown-5 is electroinactive and water soluble, but when adhered to the electrode surface with TCNQ and coated by Nafion or dissolved in the Nafion at varying concentrations, very broad reduction peaks were obtained, suggesting that the crown ether preferentially binds $\mathrm{Na}^{+}$without forming a crown ether- $\left[\mathrm{M}^{+} \mathrm{TCNQ}{ }^{-}\right]$salt. This reduced $\mathrm{Na}^{+}$ion activity at the electrode surface slows the crystal nucleation and growth process. To overcome this effect, the ionophore may need to be covalently attached to the TCNQ moiety so that ion binding by the ionophore can be coupled to the reduction of TCNQ. Similarly, anion ionophores need to be attached to TTF, however there are far fewer anion ionophores available. ${ }^{2}$

Due to the poor selectivity of the microcrystal modified electrode VISE, it is unable to be used to measure ions of interest in complex solutions such as blood. However, it may be applicable to certain solutions where the ion is in significant excess over interferent ions.

\section{Operating parameters for thin film voltammetric ion selective electrodes}

In response to the poor selectivity of the microcrystal VISE, a new thin film VISE was proposed by the authors. ${ }^{15}$ This sensor is based on a polymer supported liquid membrane attached to an electrode surface which contains a hydrophobic electroactive species, a hydrophobic supporting electrolyte, an ionophore and a support matrix (e.g. PVC). Reduction or oxidation of the electroactive species requires ion transfer of a counter ion from the test solution into the membrane solvent to maintain charge neutrality. The ion transferred is mainly governed by the ionophore, and ensures very high selectivity for the ion of interest.

In the case of a $\mathrm{K}^{+}$sensor, reduction of TCNQ in a NPOE plasticized PVC supported membrane with THATPB supporting electrolyte and bis[(benzo-15-crown-4)-4'-ylmethyl]-
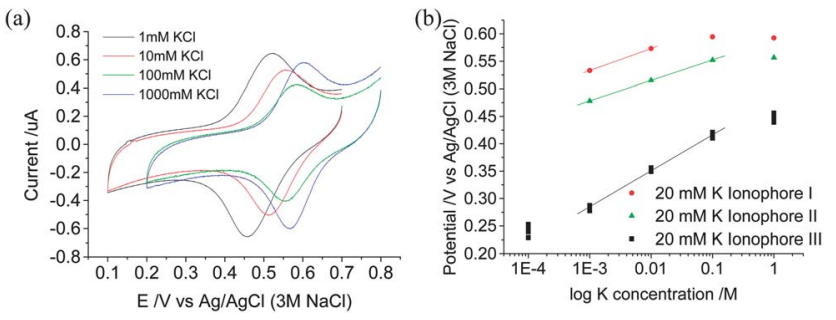

Fig. 3 (a) Cyclic voltammetry of $2.5 \mathrm{mM}$ TCNQ with $20 \mathrm{mM} \mathrm{K}$ ionophore II and (b) sensitivity of a thin film VISE at a scan rate of $100 \mathrm{mV} \mathrm{s}^{-1}$ varying $\mathrm{KCl}$ concentration with $20 \mathrm{mM} \mathrm{K}$ ionophore I, II or III.

pimelate ( $\mathrm{K}$ ionophore $\mathrm{II}$ ) in $\mathrm{KCl}_{(\mathrm{aq})}$ generates cyclic voltammograms with small, reversible, symmetrical reduction and oxidation peaks, with a peak separation of around $30-40 \mathrm{mV}$ (Fig. 3a). As a new membrane is used for every measurement, the different peak heights at each analyte concentration are attributed to variation in the membrane thickness. Only one potential cycle was required to obtain the $E_{\mathrm{m}}^{0 \prime}$ value, unlike the microcrystal VISE, which required multiple potential cycles to stabilize the nucleation and growth process. From a sensing perspective, this allows sample testing to be obtained more rapidly with the thin film VISE.

A similar outcome is achieved with $20 \mathrm{mM}$ valinomycin (K ionophore $\mathrm{I})^{15}$ as an alternative to $\mathrm{K}$ ionophore $\mathrm{II}$, but the $E_{\mathrm{m}}^{0^{\prime}}$ value at comparable $\mathrm{K}^{+}$concentrations has shifted by about $50 \mathrm{mV}$ to more positive values (Fig. $3 \mathrm{~b}$ ). The reduction and oxidation processes are stable from 1-1000 $\mathrm{mM} \mathrm{K}^{+}$over several cycles of the potential. The sensitivity profile of the K ionophore II film (Fig. 3b) shows a log linear trend from 1-100 $\mathrm{mM} \mathrm{KCl}$ with a gradient of $58 \mathrm{mV}$ per decade. At high $\mathrm{K}^{+}$concentrations, a sensitivity plateau (upper detection limit) was seen under certain conditions for both $\mathrm{K}$ ionophore II and valinomycin, with valinomycin forming a plateau at lower concentrations of KCl. BME 44 (K ionophore III) had a sensitivity of $65 \mathrm{mV}$ per decade, which was only slightly reduced at $1 \mathrm{M} \mathrm{KCl}$ (Fig. 3b). Lowering the $\mathrm{K}$ ionophore II concentration to 10 and $5 \mathrm{mM}$ maintains the sensitivity but reduces the $E_{\mathrm{m}}^{0 \prime}$ at similar concentrations of $\mathrm{K}^{+}$and reduces the upper detection limit (Fig. 4a).

A related response was seen with $\mathrm{Na}^{+}$sensors in $\mathrm{NaCl}_{(\mathrm{aq})}$. 4-Tert-butylcalix[4]arene-tetraacetic acid tetraethylester (Na ionophore $\mathrm{X})$ and bis[(12-crown-4)methyl] dodecylmethylmalonate (Na ionophore VI) were examined as Na ionophores (Fig. 5a). The $E_{\mathrm{m}}^{0^{\prime}}$ of $\mathrm{Na}$ ionophore $\mathrm{X}$ is more positive than $\mathrm{Na}$ ionophore VI by
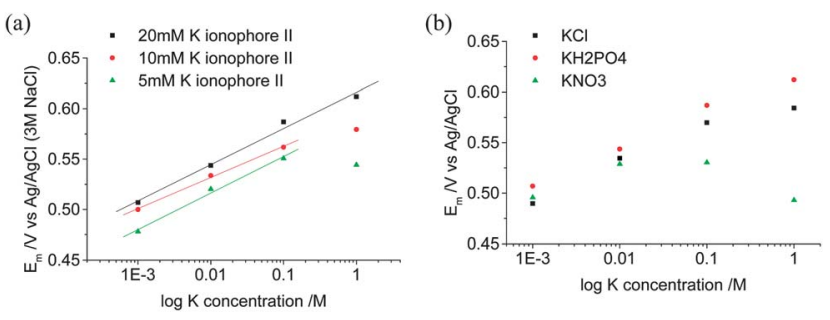

Fig. 4 Sensitivity of a thin film VISE at a scan rate of $100 \mathrm{mV} \mathrm{s}^{-1}$ varying $\mathrm{K}^{+}$ concentration (a) with a $\mathrm{PO}_{4}{ }^{3-}$ counter ion and varying $\mathrm{K}$ ionophore II concentration, and (b) $20 \mathrm{mM} \mathrm{K}$ ionophore II with varying $\mathrm{K}^{+}$counter ion. 

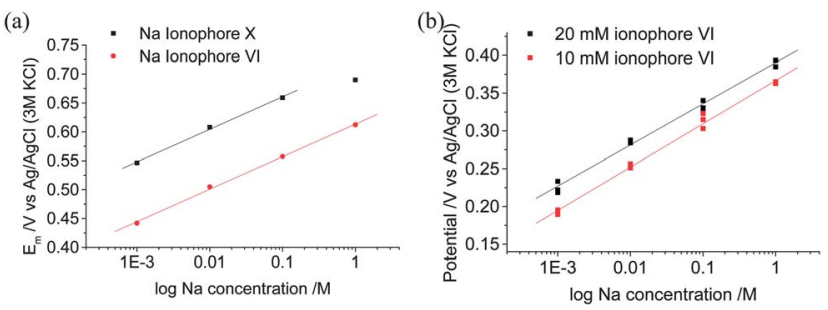

Fig. 5 Sensitivity of a thin film VISE at a scan rate of $100 \mathrm{mV} \mathrm{s}^{-1}$ varying $\mathrm{NaCl}$ concentration (a) with $20 \mathrm{mM} \mathrm{Na}$ ionophore VI or $\mathrm{X}$, and (b) varying Na ionophore VI concentration.

approximately $100 \mathrm{mV}$ and the sensitivity, which is $56 \mathrm{mV}$ per decade at low $\mathrm{Na}^{+}$concentrations, decreases above $100 \mathrm{mM} \mathrm{Na}^{+}$ while Na ionophore VI shows no decrease in sensitivity up to $1 \mathrm{M}$ $\mathrm{NaCl}$. The concentration of $\mathrm{Na}$ ionophore VI was varied to see what affect it had on the sensitivity of the film (Fig. 5b). Once again the sensitivity is close to Nernstian and the correlation coefficient of the film is high, but by reducing the concentration of ionophore in the film, the $E_{\mathrm{m}}^{0 \prime}$ value is shifted to less positive potentials.

The counter-ion of the $\mathrm{K}^{+}$salt (Fig. $4 \mathrm{~b}$ ) was changed with $20 \mathrm{mM} \mathrm{K}$ ionophore II present in the membrane solvent. The upper detection limit for $\mathrm{KCl}$ was $100 \mathrm{mM}$, the more hydrophilic $\mathrm{KH}_{2} \mathrm{PO}_{4}$ had an upper detection limit $>1 \mathrm{M}$ and the lipophilic $\mathrm{KNO}_{3}$ had an upper detection limit of $10 \mathrm{mM}$ with a reversal in gradient at high concentrations. The same trend was seen with the $\mathrm{Na}^{+}$sensor, with lowering of the thin film sensitivity at high $\mathrm{Na}^{+}$concentrations when the counter ion is changed from $\mathrm{Cl}^{-}$ to $\mathrm{SO}_{4}{ }^{2-}$ and $\mathrm{NO}_{3}{ }^{-}$(Fig. 6). $20 \mathrm{mM}$ Na ionophore VI did not show any decrease in sensitivity at $1 \mathrm{M} \mathrm{NaCl}$ nor up to $100 \mathrm{mM}$ with other $\mathrm{Na}^{+}$salts. $1 \mathrm{M} \mathrm{Na}_{2} \mathrm{SO}_{4}$ gave a slight decrease in sensitivity but $1 \mathrm{M} \mathrm{NaNO}_{3}$ has an $E_{\mathrm{m}}^{0^{\prime}}$ value more negative than $100 \mathrm{mM} \mathrm{NaNO}_{3}$.

In an effort to further understand the upper detection limit of the thin film VISE, a Na ${ }^{+}$(Na ionophore VI) and $\mathrm{K}^{+}$(K ionophore II) VISE were created and allowed to sit in a solution of concentrated primary analyte salt for varying lengths of time. The $\mathrm{Na}^{+}$VISE did not suffer from Donnan exclusion failure, and when left in a solution of $100 \mathrm{mM} \mathrm{NaCl}$, no shift in $E_{\mathrm{m}}^{0 \prime}$ was seen over 30 seconds. In contrast, the $\mathrm{K}^{+}$VISE when left in $1 \mathrm{M} \mathrm{KCl}$ showed a reduction in $E_{\mathrm{m}}^{0^{\prime}}$ of $20 \mathrm{mV}$ over 120 seconds which represents a problem with respect to sensing.

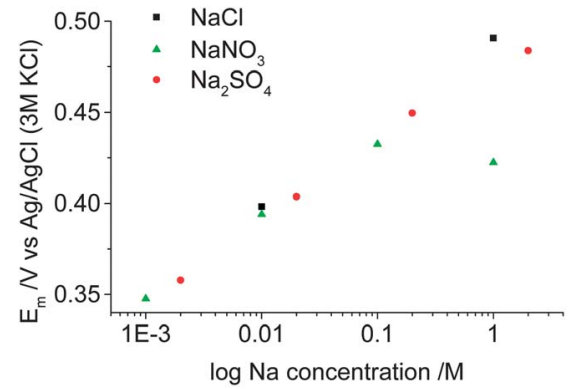

Fig. 6 Sensitivity of a thin film VISE with $20 \mathrm{mM}$ Na ionophore VI at a scan rate of $100 \mathrm{mV} \mathrm{s}^{-1}$ varying $\mathrm{Na}^{+}$counter ion.
The reversal in the sensitivity plot has been seen previously with potentiometric ISEs at similar concentrations of salt and was termed the upper detection limit. ${ }^{25,26}$ The upper detection limit is very similar to the Donnan exclusion failure reported previously, ${ }^{15}$ the limit being affected by the lipophilicity of the counter ion in this case $\mathrm{PO}_{4}{ }^{3-}<\mathrm{Cl}^{-}<\mathrm{NO}_{3}{ }^{-}$(increased lipophilicity reducing the upper detection limit), formation constant $\left(\beta_{\mathrm{IL}}\right)$ (increased $\beta_{\mathrm{IL}}$ reducing the upper detection limit) and the activity of ionophore in the membrane (reduced activity reducing the upper detection limit). The upper detection limit has been explained as the occupation of a large number of ionophore sites in the membrane; further increasing the salt concentrations in the analyte solution results in extraction of counter ion into the film. Hence, the selective cation sensor becomes a non-selective (responding to the Hofmeister series) anion sensor. Valinomycin, $\mathrm{K}$ ionophore II and III have $\log \beta_{\mathrm{IL}}$ of $11.63 \pm 0.08,10.22 \pm 0.07$ and 10.04 respectively. ${ }^{27}$ The low $\beta_{\text {IL }}$ of $\mathrm{K}$ ionophore III results in the highest upper detection limit of the ionophores tested in this series and has therefore been used in all subsequent $\mathrm{K}^{+}$testing.

Both $\mathrm{Na}$ ionophores are believed to form $1: 1$ complexes and are highly lipophilic, however Na ionophore $\mathrm{X}$ has $\log \beta_{\mathrm{IL}}=$ $10.27 \pm 0.05$ in NPOE as opposed to $9.19 \pm 0.11$ for Na ionophore VI. ${ }^{27}$ This order of magnitude difference in $\log \beta_{\mathrm{IL}}$ for Na ionophore $\mathrm{X}$ would make $\mathrm{Na}^{+}$more soluble in the membrane and explain the shift in $E_{\mathrm{m}}^{0 \prime}$ to more positive potentials. It would also result in a higher percentage of the ionophore being bound to $\mathrm{Na}^{+}$lowering its activity in the film, hence reducing its sensitivity at higher concentration. Therefore, Na ionophore VI was used for all subsequent $\mathrm{Na}^{+}$testing.

The $\mathrm{K}^{+}$VISE with $20 \mathrm{mM} \mathrm{K}$ ionophore II appears to be slightly $\mathrm{pH}$ sensitive from $\mathrm{pH} 3-8$ while a $\mathrm{pH}$ of 11 severely affects the $E_{\mathrm{m}}^{0 \prime}$. The sensitivity of the $\mathrm{Na}^{+}$sensor to $\mathrm{pH}$ was also tested from pH 3-10. Despite some variability between samples, no trend could be seen over this pH range indicating a very high selectivity for $\mathrm{Na}^{+}$over $\mathrm{H}^{+}$.

\section{Ionic liquids as thin film voltammetric ion selective electrode membrane solvents}

Room temperature ionic liquids are now being advocated as alternative solvents for use in many branches of chemistry because of their negligible vapour pressure, low toxicity, high chemical, electrochemical and thermal stability, high conductivity and the ability to dissolve a wide range of organic and inorganic compounds. ${ }^{16,28-38}$ In the sensing field, ionic liquids in contact with a quartz crystal microbalance ${ }^{39,40}$ have recently been used to determine organic vapours. The sensing mechanism in this example is based on the fact that the viscosity of the ionic liquid contained in a membrane adhered to a quartz crystal surface decreases significantly upon dissolution of even a small amount of volatile organic solvent. The viscosity change is detected as a frequency shift of the oscillating quartz crystal. However, few other applications of ionic liquids to the field of electrochemical ion sensing appear to have been reported. In the present study, the possible replacement of both the membrane solvent and supporting electrolyte of the thin film 


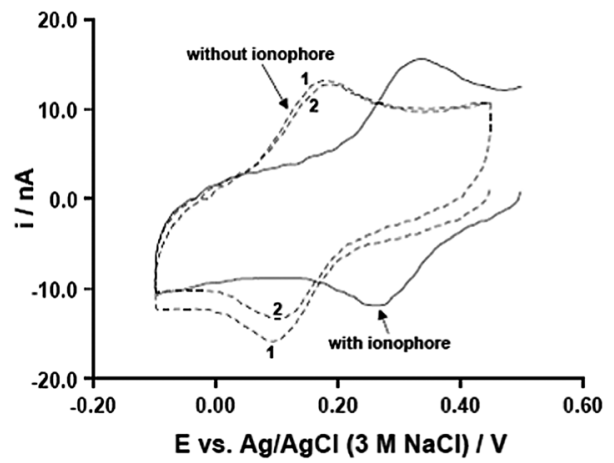

Fig. 7 Voltammograms obtained at a scan rate of $0.1 \mathrm{~V} \mathrm{~s}^{-1}$ for an ionic liquid based $\mathrm{K}^{+}$voltammetric sensor in contact with an aqueous $0.1 \mathrm{M} \mathrm{KCl}$ solution when aph4.cph12 is used as the membrane solvent and containing $2.5 \mathrm{mM}$ TCNQ and $25 \mathrm{mM}$ valinomycin. The numbers 1 and 2 refer to the first and second cycle of the potential respectively.

VISE by an ionic liquid has been investigated. Three different moderately water insoluble ionic liquids, emim.tfsa, P14.tfsa and aph4.cph12 were considered for this purpose (Fig. S1†).

Pure ionic liquids ${ }^{\mathbf{4 1}}$ or the mixture of ionic liquid with $\mathrm{NPOE}^{42}$ recently have been used as membrane solvents for anion sensing application using either voltammetric ${ }^{\mathbf{4 1}}$ or potentiometric $^{42}$ methods with some success. To form a voltammetric ion sensor, $2.5 \mathrm{mM}$ TCNQ and $25 \mathrm{mM}$ valinomycin were dissolved in the ionic liquid, with the other membrane components being as described in the Experimental section and ref. 15. This coating solution does not contain THATPB and as a consequence does not undergo a colour change with time as noted previously when TCNQ and TPB react. ${ }^{15}$ Use of aph4.cph12 produces the most stable voltammetry, which is attributed to its relatively low solubility in the aqueous phase, which minimize loss of membrane solvent. A voltammogram obtained in $0.1 \mathrm{M} \mathrm{KCl}_{(\mathrm{aq})}$ is shown in Fig. 7. The small peak current relative to that found when other non-volatile solvents are used as the membrane solvent (e.g. Fig. 3a) is attributed to the very high viscosity of aph4.cph12. ${ }^{43}$

In the absence of the ionophore, the transfer of $\mathrm{K}^{+}$into the membrane solvent phase is much less favourable. In this case, the ratio of the reduction and the oxidation peak currents remains close to unity and the peak current does not decrease significantly upon cycling of the potential, because the anion of the ionic

Table $2 E_{\mathrm{m}}^{0^{\prime}}$ values of an ionic liquid based voltammetric sensor ${ }^{a}$ in the presence of $0.1 \mathrm{M}$ cation $^{b}$ solutions

$E_{\mathrm{m}}^{0^{\prime}} / \mathrm{V}$ vs. $\mathrm{Ag} / \mathrm{AgCl}$

Without ionophore With ionophore

Ion present in the membrane present in the membrane

$\begin{array}{lll}\mathrm{K}^{+} & 0.140 & 0.305\end{array}$

$\mathrm{Na}^{+} \quad 0.180 \quad 0.200$

$\mathrm{NH}_{4}{ }^{+} \quad 0.130 \quad 0.340$

$\begin{array}{lll}\mathrm{Ca}^{2+} & 0.155 & 0.330\end{array}$

${ }^{a}$ Membrane compositions are the same as described in the caption to Fig. $7 .{ }^{b} 0.1 \mathrm{M}$ aqueous chloride solution. $\nu=0.1 \mathrm{~V} \mathrm{~s}^{-1}$. liquid, rather than electrogenerated $\mathrm{TCNQ}^{-}$, can transfer into the aqueous phase in order to maintain charge neutrality during the course of a cyclic voltammetric experiment.

The voltammetric response of the ionic liquid based voltammetric sensor in the presence of $0.1 \mathrm{M} \mathrm{K}^{+}, \mathrm{Na}^{+}, \mathrm{NH}_{4}{ }^{+}$or $\mathrm{Ca}^{2+}$ in the aqueous phase is summarized in Table 2 . The selectivity to $\mathrm{K}^{+}$against other cations is less than reported with a conventional membrane. Moreover, the slope for a calibration plot of $E_{\mathrm{m}}^{0^{\prime}}$ versus $\log _{10}\left[\mathrm{~K}^{+}\right]$of less than $20 \mathrm{mV}$ per decade change in concentration is obtained. This is most likely the result of dissolution of a small amount of ionic liquid, even though its solubility in water is low. It needs to be remembered that a $\mathrm{mM}$ concentration level of ionic liquid can be generated in the aqueous phase when only $0.1 \%$ of the ionic liquid is dissolved in this phase. Thus, other combinations of ionic liquid based membranes will need to be developed to achieve higher selectivity and sensitivity for the determination of $\mathrm{K}^{+}$.

\section{Application of voltammetric ion selective electrodes to screen- printed electrodes}

Commercially viable electrochemical sensors for fieldwork need to be low cost, as well as reproducible. Initially the microcrystal VISE approach was attempted on screen-printed planar macrodisc graphite electrodes. ${ }^{18}$ Mechanical attachment of TCNQ and TTF provides no means of controlling the crystal size. Furthermore, grinding the hard TTF crystals onto the screen-printed electrode can damage the relatively soft carbon ink electrode. More homogeneous crystals are produced by drop casting a solution onto the electrode surface and allowing the solvent to evaporate, although commonly used organic solvents such as acetonitrile or THF dissolve the screen-printed electrodes. Alternatively, drop casting from a distillable ionic liquid such as DIMCARB may be used. ${ }^{44}$ Vapour deposition of TCNQ or TTF onto the electrodes eliminates the need for a solvent, while still allowing control of the quantity deposited. However, careful control is required to ensure deposition only occurs on the working electrode, especially as contact between TCNQ and silver (in the reference electrode) will result in AgTCNQ formation. ${ }^{45}$ Grinding the crystals with a mortar and pestle to produce a powder with relatively homogeneous crystal size and gently brushing these microcrystals onto the electrode surface with a tissue, prevents any damage to the electrode. Four different sized TCNQ crystal powders were created for this assessment. The mass of TCNQ present on the electrode surface using this method is variable and unknown. The current magnitude but not the peak positions, as needed for sensing applications, varied with crystal size. This method therefore allows sensing with screen-printed electrodes. The voltammetric peaks when $\operatorname{NaCl}_{(\mathrm{aq})}$ was used as the supporting electrolyte (Fig. S3†) were less symmetrical than on standard electrodes and more potential cycles were required to obtain reproducible peak potentials.

Use of TCNQ dissolved in the carbon ink as the working electrode removes the need for an additional adhesion method. Use of $5 \% \mathrm{w} / \mathrm{w}$ produced multiple broad voltammetric peaks (Fig. S4 $\dagger$ ). Reduction of the TCNQ percentage in the ink may improve the response. 
Screen-printed electrodes, designed as above, do not have the reference electrode isolated from the test solution. ${ }^{18}$ In this case, if $\mathrm{NaCl}$ is present as the electrolyte, the reference potential $\left(E_{\text {ref }}\right)$ should shift in response to the chloride activity in a Nernstian manner of $59 \mathrm{mV}$ per decade change (eqn (6)).

$$
E_{\mathrm{ref}}=E^{0^{\prime}}-2.303 \frac{R T}{F} \log a_{\mathrm{Cl}^{-}}
$$

Combining the potential shift of the microcrystal TCNQ sensor due to changing $\mathrm{Na}^{+}$concentration (eqn (1)) with that of the $\mathrm{Ag} / \mathrm{AgCl}$ reference electrode (eqn (6)) and ignoring activity coefficient contributions gives:

$$
\begin{gathered}
E_{\mathrm{m}}=E^{0^{\prime}}-S \log \left[\mathrm{X}^{-}\right]-\left(E^{0^{\prime}}-2.303 \frac{R T}{F} \log \left[\mathrm{Cl}^{-}\right]\right) \\
E_{\mathrm{m}}=E^{0^{\prime}}-E^{0^{\prime \prime}}+0.0444 \log \left[\mathrm{Na}^{+}\right]+0.059 \log \left[\mathrm{Cl}^{-}\right]
\end{gathered}
$$

In these circumstances, addition of $\mathrm{NaCl}$ will result in a predicted apparent $E_{\mathrm{m}}$ shift of $103.4 \mathrm{mV}$ per decade change in concentration of $\mathrm{NaCl}$ (Fig. S2 $\dagger$ ). In contrast, the apparent potential shift of the microcrystal TTF sensor (eqn (2)) to chloride when using the screen-printed electrodes in this form is predicted to reduce the sensitivity to $14.6 \mathrm{mV}$ per decade change in concentration (eqn (9)-(11)).

$$
\begin{gathered}
E_{\mathrm{m}}=E^{0^{\prime}}-S \log \left[\mathrm{X}^{-}\right]-\left(E^{0^{\prime \prime}}-2.303 \frac{R T}{F} \log \left[\mathrm{Cl}^{-}\right]\right) \\
E_{\mathrm{m}}=E^{0^{\prime}}-E^{0^{\prime \prime}}-0.0444 \log \left[\mathrm{Cl}^{-}\right]+0.059 \log \left[\mathrm{Cl}^{-}\right] \\
E_{\mathrm{m}}=E^{0^{\prime}}-E^{0^{\prime \prime}}+0.0146 \log \left[\mathrm{Cl}^{-}\right]
\end{gathered}
$$

Experimentally, close compliance to eqn (11) was also found.

The thin film VISE allows fast, accurate determination of ions given a suitable ionophore. A PVC supported thin film VISE was applied to all 4 screen-printed electrodes (left strip of Fig. 8). The top two electrodes had the membrane solvent applied and allowed to dry in air. A ring can be seen in the blue dielectric ink around the black graphite working electrode that is due to the THF dissolving the ink. The bottom two electrodes had the membrane solvent applied and then the pipette was gently dragged over the electrode; clearly the ink has been dissolved by the THF. The high solubility of the ink in THF could affect the electrode area and conductivity, which will reduce the reproducibility of the electrodes, so another support matrix is required that can replace $\mathrm{PVC}$, the only component that requires the use of THF. The replacing supporting matrix needs to be redox inactive, chemically inert and not water-soluble. The dielectric ink used to form the electrodes is a possible candidate as it meets these criteria. A dielectric ink-supported thin film VISE was created (see below for details) and applied to the screen-printed electrodes (right strip in Fig. 8). Now no ring patterns can be seen in the dielectric ink of the strip, and even when gently scratched by the pipette tip (bottom two electrodes), no significant damage occurred.

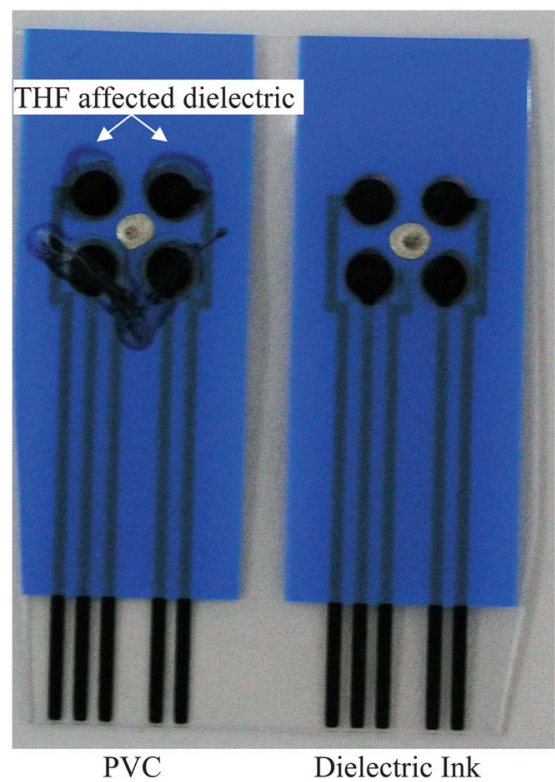

Fig. 8 Image of screen-printed electrodes after application of a thin film to the working electrode. The electrode array on the left has been coated with a PVC supported thin film while the right electrode array has been coated with a dielectric ink-supported thin film. The top two electrodes have had the film applied and allowed to evaporate; the bottom two electrodes have been gently scratched after the film was applied.

Varying masses of dielectric ink were combined with the usual amounts of NPOE, TCNQ (dissolved in THF), THATPB (dissolved in THF) and ionophore and then drop cast onto a GC working electrode. Cyclic voltammetry of the dielectric ink membrane is very similar to the PVC thin film VISE (Fig. S5†). At high dielectric: NPOE ratios, the membrane forms an insulating layer over the electrode surface, resulting in a large $i R_{\mathrm{u}}$ drop. When a mass of $12.5 \mathrm{mg}$ dielectric is used, a reduction peak is formed at $0.288 \mathrm{~V}$ and an oxidation peak at $0.353 \mathrm{~V}$, giving a peak separation of $65 \mathrm{mV}$. Increasing the volume of film deposited on the electrode surface from $0.2 \mu \mathrm{L}$ to $0.5 \mu \mathrm{L}$ (Fig. S5b $\mathrm{b}^{\dagger}$ ) increases the charge passed but also increases the peak separation as was seen with the PVC supported film, ${ }^{\mathbf{1 5}}$ therefore $0.2 \mu \mathrm{L}$ was used for all subsequent experiments.

Using a $12.5 \mathrm{mg}$ dielectric ink-supported VISE without ionophore (Fig. S6†), the first potential cycle produces a symmetrical reduction peak at $-0.5 \mathrm{~V} v s$. $\mathrm{Ag} / \mathrm{AgCl}$, switching the scan direction showed a broad oxidation peak centered at $0.5 \mathrm{~V}$. The second cycle had reduced reduction and oxidation currents, indicating the $\mathrm{TCNQ}^{-}$is being transferred out of the film into the aqueous solution, as occurred with the PVC supported VISE. $^{15}$

The sensitivity of the dielectric ink-supported VISE with $20 \mathrm{mM}$ Na ionophore VI was the same as the PVC supported VISE being $49.3 \mathrm{mV}$ versus $\log _{10}\left[\mathrm{Na}^{+}\right]$. The sensitivity of the dielectric inksupported VISE with $20 \mathrm{mM} \mathrm{K}$ ionophore III was also similar to the PVC supported VISE being $61.4 \mathrm{mV}$ versus $\log _{10}\left[\mathrm{~K}^{+}\right]$.

Creation of a $\mathrm{Ca}$ ionophore II thin film VISE was also attempted using the dielectric ink. Small peak separation similar to the $\mathrm{Na}$ and $\mathrm{K}$ thin film VISE occurred at high $\mathrm{Ca}^{2+}$ 
concentrations, but large peak separation similar to the microcrystal VISE ${ }^{12}$ occurred at low $\mathrm{Ca}^{2+}$ concentrations. It is assumed that there is something in the ink which is specifically binding $\mathrm{Ca}^{2+}$ and that the use of another ink is needed to solve the problem.

As a final proof of principle, the Na ionophore VI dielectric ink-supported thin film VISE was applied to several screenprinted electrodes. As the working electrodes are smaller than the GC electrode, the $0.2 \mu \mathrm{L}$ droplet was spread over two electrodes. Using the screen-printed $\mathrm{Ag} / \mathrm{AgCl}$ reference electrode on the strip, the VISE shifted in response to changing $\mathrm{Na}^{+}$ concentration (49.3 $\mathrm{mV}$ versus $\log _{10}\left[\mathrm{Na}^{+}\right]$) while the $\mathrm{Ag} / \mathrm{AgCl}$ shifted in response to the $\mathrm{Cl}^{-}$concentration $(58 \mathrm{mV}$ versus $\left.\log _{10}\left[\mathrm{Cl}^{-}\right]\right)$. The sensitivity of the electrode to $\mathrm{NaCl}$ was $106.4 \mathrm{mV}$ versus $\log _{10}\left[\mathrm{Na}^{+}\right]$, which is very close to the expected $107 \mathrm{mV}$.

\section{Methods to reference a voltammetric ion selective electrode}

A well defined and stable reference potential is required for ion selective electrode measurements. Standard reference electrodes, such as $\mathrm{Ag} / \mathrm{AgCl}(3 \mathrm{M} \mathrm{KCl})$ with controlled inner filling solutions and a salt bridge are suitable for lab use, but not in point of care devices. As the reference electrode on the screenprinted electrodes is exposed to the test solution, a change in the solution $\mathrm{Cl}^{-}$concentration will shift the reference electrode potential. To remove the effect of reference electrode potential shift, separation of the reference electrode by a membrane or coating is needed or a calibration redox couple may be required to provide a reference potential. The one electron reduction of water soluble $\left[\mathrm{Ru}\left(\mathrm{NH}_{3}\right)_{6}\right] \mathrm{Cl}_{3}$ according to the half reaction $\mathrm{Ru}\left(\mathrm{NH}_{3}\right)_{6}{ }^{3+}+\mathrm{e}^{-} \rightleftharpoons \mathrm{Ru}\left(\mathrm{NH}_{3}\right)_{6}{ }^{2+}$ may be used. The increase in chloride concentration provided by the use of a chloride salt may be overcome by the use of $\left[\mathrm{Ru}\left(\mathrm{NH}_{3}\right)_{6}\right]\left(\mathrm{PF}_{6}\right)_{3}$ or other suitable salt. However, a neutral redox active species that undergoes electron transfer at potentials well removed from the $\mathrm{TCNQ}^{\mathrm{o}-}$ and $\mathrm{TTF}^{\mathrm{O} /+}$ voltammetry may be preferred. The reduction of benzoquinone to hydroquinone displays reversible voltammetry on EPG according to the reaction benzoquinone $+2 \mathrm{H}^{+}+2 \mathrm{e}^{-} \rightleftharpoons$ hydroquinone ${ }^{46}$ (Fig. S7a $\dagger$ ) and was well removed from the TTF process, but exhibited less reproducible voltammetry on the screen-printed electrodes, which may be due to adsorption. ${ }^{47}$ As a calibration redox couple for the TCNQ sensor, oxidation of various substituted ferrocenes were examined with 1,1'-ferrocenedicarboxylic acid (Fig. S7b $\dagger$ ) displaying reversible voltammetry according to the reaction $\mathrm{Fc}(\mathrm{COOH})_{2} \rightleftharpoons \mathrm{Fc}(\mathrm{COOH})_{2}{ }^{+}+\mathrm{e}^{-}$, which is well removed from the TCNQ response at $\mathrm{pH} 9$. However, $\mathrm{Fc}(\mathrm{COOH})_{2}$ is less soluble at $\mathrm{pH} 7.5$, relevant to biological conditions, reducing the peak current obtained during voltammetry. Application of Nafion over the electrode to prevent dissolution of $\mathrm{TCNQ}^{-}$also significantly reduced the current magnitude of the $\mathrm{Fc}(\mathrm{COOH})_{2}$ voltammetry by blocking the electrode surface (Fig. S7c $\dagger$ ). To increase the current magnitude, $\mathrm{Fc}(\mathrm{COOH})_{2}$ could be mechanically adhered to the electrode and placed under Nafion, but care is now needed with $i R_{\mathrm{u}}$ drop (Fig. S7d $\dagger$ ). Alternatively, a through hole in the Nafion or thin film coating could be created to allow access of a solution phase calibration redox species to the electrode surface. A small hole was made in a thin film VISE, exposing the electrode before placing it into a solution containing $\mathrm{Ru}\left(\mathrm{NH}_{3}\right)_{6}{ }^{3+}$. A response was then obtained for both the VISE and the $\mathrm{Ru}\left(\mathrm{NH}_{3}\right)_{6}{ }^{3+/ 2+}$ couple allowing the VISE $E_{\mathrm{m}}^{0^{\prime}}$ to be referenced to the $\mathrm{Ru}\left(\mathrm{NH}_{3}\right)_{6}{ }^{3+/ 2+} E_{\mathrm{m}}^{0^{\prime}}$ (Fig. S8 $\dagger$ ). While this method appears suitable for VISE calibration, placing a hole in the membrane may not be reproducible and could affect the sensitivity or selectivity of the sensor. It is therefore recommended that a separate working electrode be used for the determination of the $\mathrm{Ru}\left(\mathrm{NH}_{3}\right)_{6}{ }^{3+/ 2+} E_{\mathrm{m}}^{0^{\prime}}$ to calibrate the VISE.

These methods all require the addition of a redox calibrant species to the sample. Another possible method for calibrating the electrode potential is referencing to the transfer of an ion of known activity across a thin film VISE. A reference thin film VISE could be used, in a variety of formats. A thin film VISE containing ionophore and redox species could be used if the ion species, ionophore and redox species activities are accurately known or have been calibrated separately. Other combinations of thin film VISE with or without the redox species and ionophore could also be used. The most versatile method would be to omit the redox species and ionophore completely and measure the peak potentials associated with ion transfer of a suitably hydrophobic ion, such as $\mathrm{ClO}_{4}{ }^{-}$or $\mathrm{PF}_{6}{ }^{-15}$

\section{Application of voltammetric ion selective electrodes to sea water and drink samples}

All of the work published to date in relation to the microcrystal and thin film VISEs detailed in this article have been in solutions with only primary or a single interfering ion to determine Nicolsky-Eisenman type selectivity coefficients. The selectivity data indicate the microcrystal VISE will only respond correctly in sensing applications when the ion of interest is in a considerable excess over other ions. ${ }^{12}$ The thin film VISE should have sufficient selectivity to measure ions of interest even when their activity is significantly less than potentially interfering ions. ${ }^{15}$ Seawater, typically having a composition of the kind given in Table $3,{ }^{48}$ has a large excess in $\mathrm{Na}^{+}$that should meet the conditions required for the microcrystal VISE.

The TCNQ microcrystal VISE in seawater displayed welldefined voltammetry from the tenth cycle of the potential (Fig. S9a $\dagger$ ) and via reference to a calibration curve of known concentrations of pure electrolyte, the $\mathrm{Na}^{+}$concentration in seawater was determined to be $575 \mathrm{mM}$, in reasonable agreement with the $521 \mathrm{mM}$ concentration obtained with a potentiometric ISE (Table 3).

The TTF microcrystal VISE in contact with seawater exhibits well-defined voltammetry from the fifth cycle of the potential (Fig. S9b†). Interpolation from a TTF calibration curve in pure electrolyte, the $\mathrm{Cl}^{-}$concentration was determined to be $536 \mathrm{mM}$, which is close to the $563 \mathrm{mM}$ determined by a spectrophotometric technique (Table 3 ).

To ensure the thin film VISE can be used in complex matrices, seawater and a sports drink were obtained to determine their $\mathrm{Na}^{+}$and $\mathrm{K}^{+}$concentrations and a milk sample was used to test the reliability of the $\mathrm{Ca}^{2+}$ sensor. The values were compared to those claimed by the manufacturer and to values 
Table 3 Comparison of proposed VISEs with commercial ISES, spectrophotometric technique and manufacturer claimed concentrations in seawater and drink samples

\begin{tabular}{|c|c|c|c|c|c|c|c|c|c|c|c|c|}
\hline \multirow[b]{2}{*}{ Sample } & \multicolumn{4}{|l|}{$\mathrm{Na}^{+} / \mathrm{mM}$} & \multicolumn{3}{|l|}{$\mathrm{K}^{+} / \mathrm{mM}$} & \multicolumn{2}{|l|}{$\mathrm{Ca}^{2+} / \mathrm{mM}$} & \multicolumn{3}{|l|}{$\mathrm{Cl}^{-} / \mathrm{mM}$} \\
\hline & Claimed & Crystal & Membrane & Commercial & Claimed & Membrane & Commercial & Membrane & Commercial & Claimed & Crystal & $\begin{array}{l}\text { Spectro- } \\
\text { photometry }\end{array}$ \\
\hline Seawater & $\sim 500$ & 575 & 495 & 521 & $\sim 10$ & 8.9 & 9.0 & - & - & 570 & 536 & 563 \\
\hline Gatorade & 21 & - & 21 & 23 & 6 & 6.7 & 8.8 & - & - & - & - & - \\
\hline Milk & - & - & - & - & - & - & - & 0.71 & 0.71 & - & - & - \\
\hline
\end{tabular}
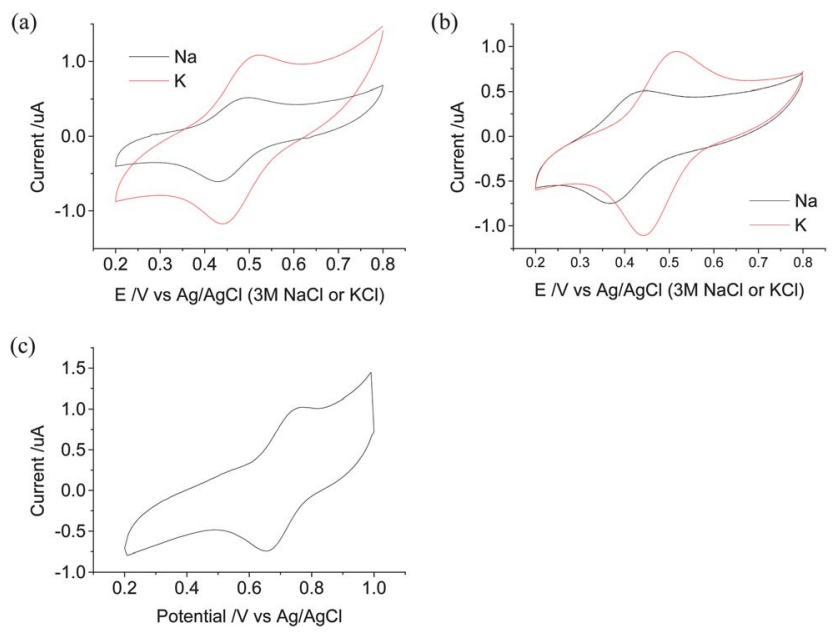

Fig. 9 Cyclic voltammetry of a thin film VISE with $20 \mathrm{mM} \mathrm{Na}$ ionophore $\mathrm{VI}$ or $\mathrm{K}$ ionophore II at a scan rate of $100 \mathrm{mV} \mathrm{s}^{-1}$ in (a) sea water and (b) Gatorade. (c) Cyclic voltammetry of a thin film VISE with $20 \mathrm{mM}$ Ca ionophore II at a scan rate of $100 \mathrm{mV} \mathrm{s}^{-1}$ in rehydrated skim milk powder.

obtained with commercial potentiometric membrane ISEs (Metrohm) (Table 3). The thin film VISEs were calibrated by creating a concentration versus $E_{\mathrm{m}}^{0^{\prime}}$ plot and the $E_{\mathrm{m}}^{0^{\prime}}$ values from the samples were used to calculate the analyte concentration. Well defined cyclic voltammograms were obtained for all of the samples (Fig. 9). All of the measurements for $\mathrm{Na}^{+}, \mathrm{K}^{+}$and $\mathrm{Ca}^{2+}$ are in excellent agreement with the commercial sensors and the manufacturers claim. Furthermore, as indicated in the previous article ${ }^{15}$ the time required for the potentiometric sensor to achieve an equilibrium state for activity measurement was significantly longer compared with a VISE.

\section{Application of a thin film voltammetric ion selective electrode to plasma and whole blood}

Initially 9 fresh plasma samples, 2 whole blood samples and 2 frozen and thawed plasma samples were collected for $\mathrm{Na}^{+}, \mathrm{K}^{+}$ and $\mathrm{Ca}^{2+}$ determination with a thin film VISE. The membrane solutions were calibrated using $1 \mu \mathrm{L}$ membrane volumes in aqueous solutions of the analyte salt before sample testing for $\mathrm{Ca}^{2+}$ and $\mathrm{K}^{+}$with a $\mathrm{Ag} / \mathrm{AgCl}(3 \mathrm{M} \mathrm{NaCl})$ reference electrode and finally $\mathrm{Na}^{+}$testing with a $\mathrm{Ag} / \mathrm{AgCl}(3 \mathrm{M} \mathrm{KCl})$ reference electrode. This testing protocol ensured the membrane solutions were functioning correctly before placing them into the samples and reduced sample contamination from the reference electrodes

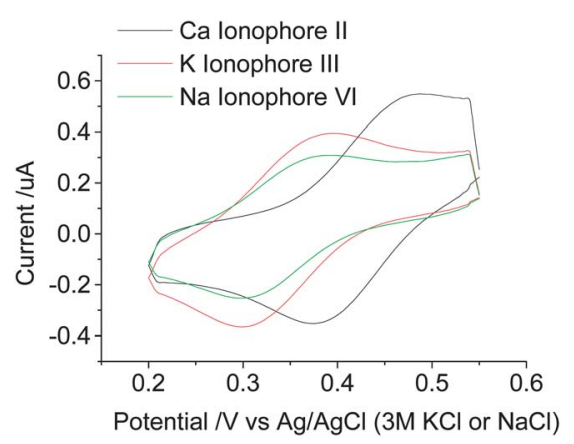

Fig. 10 Cyclic voltammetry of a $4 \mu \mathrm{L}$ thin film VISE with $20 \mathrm{mM}$ Ca ionophore II, $\mathrm{K}$ ionophore III or $\mathrm{Na}$ ionophore VI in plasma at a scan rate of $100 \mathrm{mV} \mathrm{s}^{-1}$.

(as the sample $\mathrm{Na}^{+}$concentration was much greater than $\mathrm{K}^{+}$and would be less affected by leaching of the reference electrode $\mathrm{Na}^{+}$ internal filling solution). Each measurement was performed in triplicate. With $1 \mu \mathrm{L}$ membrane volumes, the TCNQ reduction and oxidation processes in plasma didn't form a peak at scan rates from 20 to $500 \mathrm{mV} \mathrm{s}^{-1}$ (Fig. S10a†). The thickness of the thin film was increased to a $4 \mu \mathrm{L}$ droplet volume, generating well-defined reduction and oxidation peaks (but increasing the $i R_{\mathrm{u}}$ drop and measurement error) (Fig. S10b $\dagger$ ). The $4 \mu \mathrm{L}$ thin film VISE with $20 \mathrm{mM}$ Ca ionophore II, K ionophore III or Na ionophore VI at a scan rate of $100 \mathrm{mV} \mathrm{s}^{-1}$ showed the desired responses in plasma (Fig. 10).

Seven of the nine samples tested on the AEROSET 2 are in the typical range for $\mathrm{Na}^{+}$, with the other 2 being within $2 \mathrm{mM}$ of the lower limit (Table 1 and Fig. 11a). The large difference in ionic strength of plasma compared to the calibrant solutions and increased film thickness required to generate a voltammetric peak when testing plasma shifted the VISE $E_{\mathrm{m}}^{0^{\prime}}$ (calibration curve intercept). To recalibrate the VISE response, the $\mathrm{Na}^{+}$and $\mathrm{K}^{+}$calibration curves were adjusted by aligning the concentrations of one plasma sample with the results obtained using the AEROSET 2 analyzer. The calibration curve for $\mathrm{Na}^{+}$required an adjustment of $\sim 16 \mathrm{mV}$. 6 of the 9 plasma samples gave adjusted $\mathrm{Na}^{+}$activities within $10 \mathrm{mM}$ of that determined by the AEROSET 2 (Fig. 11a). The whole blood samples tested for $\mathrm{Na}^{+}$gave similar results to plasma, which would suggest red blood cells don't interfere with the $\mathrm{Na}^{+}$VISE on short time scales. The frozen/thawed plasma samples appeared to have slightly lower $\mathrm{Na}^{+}$activities than fresh plasma and may be due to some $\mathrm{Na}^{+}$being precipitated out on freezing. 
(a)
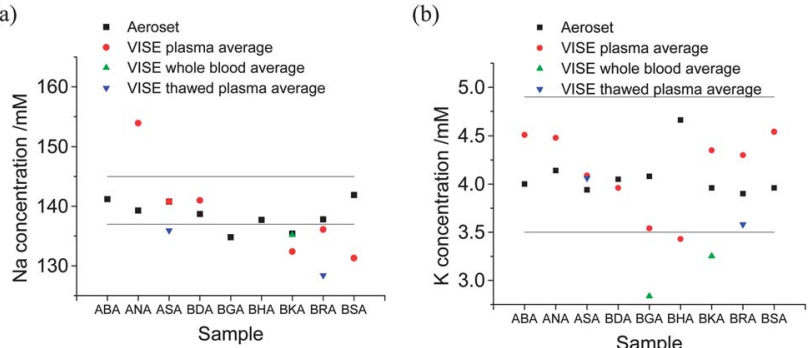

(c)

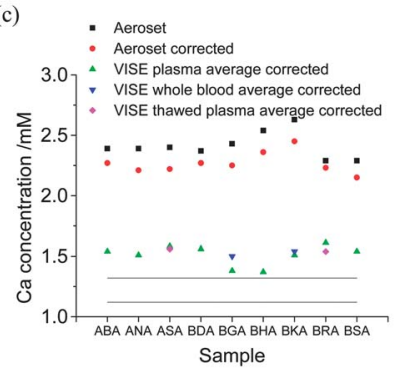

Fig. 11 Comparison of AEROSET 2 to the thin film VISE on whole blood, plasma and frozen/thawed plasma for (a) sodium, (b) potassium and (c) calcium, with corrections for albumin and heparin.

All 9 plasma samples tested on the AEROSET 2 were within the typical range for $\mathrm{K}^{+}$(Table 1 and Fig. 11b). The $\mathrm{K}^{+}$VISE calibration curve required an adjustment of $5 \mathrm{mV}$ resulting in all data being within $1.2 \mathrm{mM}$ of the AEROSET 2 values (Fig. 11b). Both the whole blood and frozen/thawed plasma samples appear to be in satisfactory agreement with the fresh plasma samples. Interestingly, both BGA and BHA plasma samples had lower than expected values for $\mathrm{Na}^{+}$and $\mathrm{K}^{+}$, which could indicate a specific interferent is affecting the results.

The typical range for $\mathrm{Ca}^{2+}$ activity in plasma is $1.12-1.32 \mathrm{mM}$ while the total $\mathrm{Ca}^{2+}$ is $2.25-2.88 \mathrm{mM}$. All 9 samples tested on the AEROSET 2 were within the total $\mathrm{Ca}^{2+}$ range when corrected for albumin concentration (eqn (3), Fig. 11c). The VISE gave $\mathrm{Ca}^{2+}$ activities of around $0.3 \mathrm{mM}$, as the blood was collected in lithium heparin tubes, the $\mathrm{Ca}^{2+}$ activity would have been lowered by binding to heparin. The tubes were labelled as containing $119 \mathrm{IU}$ of heparin; correcting for this, the $\mathrm{Ca}^{2+}$ activities are very close to the typical $\mathrm{Ca}^{2+}$ activity range (Fig. 11c). Adjustment of the calibration curve for ionic strength and membrane thickness would most likely shift all of the plasma, whole blood and frozen/thawed samples into the typical range.

Table 4 Blood calibration solution compositions

\begin{tabular}{llc}
\hline Solution & Composition $(\mathrm{mM})$ & Ionic strength \\
\hline 1 & $154.6 \mathrm{NaCl}, 0.1 \mathrm{KCl}, 0.1 \mathrm{CaCl}_{2}$, & 163.86 \\
& $5 \mathrm{Na} \mathrm{HEPES}, 4.06 \mathrm{HEPES}$ & \\
2 & $125.0 \mathrm{NaCl}, 9.0 \mathrm{KCl}, 7.0 \mathrm{CaCl}_{2}$, & 150.06 \\
& $5 \mathrm{Na} \mathrm{HEPES}, 4.06 \mathrm{HEPES}$ & \multirow{2}{*}{160.06} \\
3 & $140.0 \mathrm{NaCl}, 9.0 \mathrm{KCl}, 2.0 \mathrm{CaCl}_{2}$, & \\
& $5 \mathrm{Na} \mathrm{HEPES}, 4.06 \mathrm{HEPES}$ & \\
4 & $149.75 \mathrm{NaCl}, 3.0 \mathrm{KCl}, 0.75 \mathrm{CaCl}_{2}$, & \\
& $5 \mathrm{Na} \mathrm{HEPES}, 4.06 \mathrm{HEPES}$ & \\
5 & $146.75 \mathrm{NaCl}, 4.6 \mathrm{KCl}, 1.25 \mathrm{CaCl}_{2}$, & \\
& $5 \mathrm{Na} \mathrm{HEPES}, 4.06 \mathrm{HEPES}$ &
\end{tabular}

The initial plasma and blood testing above highlighted the need for a more appropriate calibration method. A set of 15 calibration solutions has been recommended for $\mathrm{Na}^{+}, \mathrm{K}^{+}, \mathrm{Ca}^{2+}$ and $\mathrm{H}^{+}$ISEs used for blood testing, with an ionic strength closer to plasma $(\sim 160 \mathrm{mM}) .{ }^{49}$ Calibrant solutions $1-5$ ( $\left.\mathrm{pH} 7.4\right)$ were used (solutions 1-3 for $\mathrm{Na}^{+}$and 3-5 for $\mathrm{Ca}^{2+}$ and $\mathrm{K}^{+}$calibration) (Table 4). Using a $0.2 \mu \mathrm{L}$ membrane volume, the new calibrant solutions shifted the $\mathrm{K}^{+}$and $\mathrm{Ca}^{2+} E_{\mathrm{m}}^{0^{\prime}}$ to more positive potentials, but had little effect on the $\mathrm{Na}^{+}$VISE (Fig. S11†). However, the calibrant solutions for $\mathrm{Na}^{+}$only cover a range of $29.6 \mathrm{mM}$ ( $3 \mathrm{mV})$, and with a 1-2 $\mathrm{mV}$ standard deviation, significant error in gradient could occur.

The initial plasma results also required the use of thicker VISE membranes to generate well-defined voltammetric peaks. In an effort to understand this behaviour, a series of experiments were conducted. Addition of glycerol to pure electrolyte solutions increased the solution viscosity (up to the whole blood viscosity of $4 \mathrm{cP}$; water is $1 \mathrm{cP}$ ) but had no effect on the sensor. Heparin had been added to the whole blood and plasma samples to prevent clotting. Heparin (and all other typical anticoagulants) binds free calcium, and would not be required when collecting a sample from a finger stick. Therefore, the next series of blood tests were performed without an anti coagulant to remove any potential effects on the VISE. Several articles on clinical use of ISEs suggested that the hydrophobic blood components (erythrocytes, fibrin and lipids) rapidly adsorbed onto the hydrophobic membrane, adding a junction potential (termed residual junction potential). ${ }^{50}$ To test for lipid fouling of the VISE, a fresh membrane was calibrated, dipped into a pooled, delipidated serum and then recalibrated. This treatment shifted the $\mathrm{Na}^{+}$and $\mathrm{K}^{+}$VISE $6 \mathrm{mV}$ more positive while $\mathrm{Ca}^{2+}$ had a $2 \mathrm{mV}$ negative shift. Conversely, testing a fresh $\mathrm{Na}^{+} \mathrm{VISE}$ before and after dipping the $\mathrm{Ag} / \mathrm{AgCl}(3 \mathrm{M} \mathrm{KCl})$ reference electrode into delipidated serum (not dipping the VISE), the potential shifted $3 \mathrm{mV}$ positively. Dipping both the reference electrode and $\mathrm{Na}^{+}$VISE membrane into delipidated serum generated a positive potential shift of $12 \mathrm{mV}$. After the dipping process, all of the voltammetric peak heights were smaller and had larger peak separation in the calibrant solutions, with no clearly defined peaks seen for the $\mathrm{Ca}^{2+}$ VISE. Similar results were seen when dipping the electrode into fresh serum instead of delipidated serum. While these results don't rule out lipid fouling in plasma and whole blood, they do indicate another component in serum is blocking the electrode by reducing the

Table $5 \quad E_{m}^{O^{\prime}}$ values of thin film VISEs in calibration solutions with varying levels of albumin

Potential/SD (mV) with varying concentrations of albumin $\left(\mathrm{g} \mathrm{L}^{-1}\right)$

\begin{tabular}{llll} 
VISE ionophore & 0 & 25 & 50 \\
\hline Ca ionophore II $^{a}$ & $404.6 / 2.3$ & $396.7 / 6.7$ & $406.2 /-$ \\
${\text { K ionophore } \mathrm{III}^{a}}^{\mathrm{Na} \text { ionophore } \mathrm{VI}^{b}}$ & $316.9 / 2.5$ & $342.2 / 4.1$ & $340.6 / 5.8$ \\
& $275.2 / 2.4$ & $299.7 / 3.5$ & $288.5 / 7.7$
\end{tabular}

${ }^{a}$ Calibration solution $5 .{ }^{b}$ Calibration solution 3 . 
voltammetric peak heights, increasing the peak separation and shifting the reference electrode potential.

Albumin is a hydrophilic protein present in serum and is also known to adsorb on electrode surfaces. It is approximately $66 \mathrm{kDa}$, negatively charged, known to gel in high ionic strength solutions and binds $\mathrm{Ca}^{2+}$. Typical blood ranges of albumin are $\sim 40-50 \mathrm{~g} \mathrm{~L}^{-1} .25$ or $50 \mathrm{~g} \mathrm{~L}^{-1}$ albumin was added to the calibrant solutions. All of the voltammograms using a $4 \mu \mathrm{L}$ droplet volume in the presence of albumin had reduced peak heights and increased peak separation, resulting in larger standard deviations (Table 5). The $\mathrm{K}^{+}$and $\mathrm{Na}^{+}$VISE also had positive potential shifts of $15-25 \mathrm{mV}$. This is consistent with albumin adsorbing on the membrane, blocking ion transfer and adding a junction potential. The albumin also formed a gel on the reference electrode due to the high ionic strength of the inner filling solution, adding a second junction potential. The albumin may also be increasing the ionic strength of the solution, further shifting the mid-point potentials more positively. $\mathrm{Ca}^{2+}$ activity is reduced by albumin (due to binding), and this resulted in very small Ca VISE voltammetric peak heights; at $50 \mathrm{~g} \mathrm{~L}^{-1}$ only one data point could be obtained.

Commercial potentiometric ISEs used for clinical testing generally overcome the protein fouling problem by exposing a new membrane to a plasma sample to ensure it is coated with protein, then regularly washing with cleaning solutions and recalibrating. Unfortunately, electrode fouling has more effect on voltammetric sensors than potentiometric ones. Methods to prevent albumin fouling effects on reference electrodes have been overcome previously by either reducing the inner filling solution ionic strength or using a salt bridge. However, with low-cost screen-printed electrodes, there would be no inner filling solution, eliminating this concern. VISE accuracy could be improved by addition of albumin to the calibrant solutions (with extra $\mathrm{Ca}^{2+}$ to ensure the activity is similar to plasma). Alternatively, the serum albumin concentration could be measured and used to correct the VISE potentials. The VISE could also be calibrated after contact with the plasma sample, but this would require a calibrant solution to be combined with the sensor, significantly increasing the device cost. Even with these improved calibration methods, albumin binding onto the membrane would still reduce the voltammetric peak heights and increase peak separation, increasing measurement error. Changing the ratio of PVC/plasticiser will affect the hydrophilicity of the membrane surface and may prevent albumin binding, but will also affect the membrane robustness, viscosity and conductivity. Furthermore, changes in membrane hydrophilicity may only promote binding of other molecules such as fibrin. The better route may be to replace the PVC and plasticiser with more biocompatible materials or to coat them with one such as polyethylene oxide.

\section{Conclusions}

The voltammetry of TCNQ and TTF microcrystals adhered to an electrode surface has been reported previously as a low selectivity ion-sensor. The voltammetry was improved with respect to $i R_{\mathrm{u}}$ drop by the addition of an "innocent" supporting electrolyte (buffer) to the analyte solution. Dissolved oxygen does not appear to affect the response. A polymer membrane capable of excluding certain ions from the solution and preventing dissolution of the TCNQ and TTF is required; Nafion being suitable for TCNQ voltammetry, but no suitable polymer was found for TTF voltammetry. Addition of an ionophore onto the sensor to improve selectivity resulted in a reduction in current magnitude, due to competition for the ion. Increased ion selectivity would require the ionophore to be attached to TCNQ and TTF to couple the ion-ionophore binding event with the electron transfer step. Methods for attaching the microcrystals to lowcost screen-printed electrodes were shown.

A voltammetric cation sensor that has the sensitivity and selectivity required for the detection of $\mathrm{K}^{+}, \mathrm{Na}^{+}$and $\mathrm{Ca}^{2+}$ in blood has been fabricated by employing the principle of facilitated ion transfer that accompanies an electron transfer process in a membrane phase containing a redox active species, supporting electrolyte, ionophore and membrane solvent components. The choice of ionophore has been explored through its effect on upper detection limit, allowing a tailored analyte detection range. Experiments have shown that an ionic liquid may be used to replace the membrane solvent and supporting electrolyte components in the membrane. A dielectric ink can also be used to replace the PVC and eliminate strong organic solvents, allowing the VISE to be applied to substrates that are soluble in these solvents. A range of methods to create reference electrodes based on the thin film VISE has also been proposed.

Data from two different VISEs have been compared to that obtained with commercial potentiometric ISEs and a $\mathrm{Cl}^{-}$ spectrophotometric technique in seawater, beverages and blood with results for $\mathrm{Na}^{+}, \mathrm{K}^{+}, \mathrm{Ca}^{2+}$ and $\mathrm{Cl}^{-}$in good agreement. This demonstrates the ability of both VISEs to determine the ion activity in complicated solutions with sufficient sensitivity and selectivity. The drift and long measurement times associated with potentiometric ISEs suggest that VISEs are able to provide more accurate and rapid ion concentrations given suitable calibrant solutions. The thin film VISE also allows measurement of $\mathrm{Ca}^{2+}$ activity rather than total calcium, allowing more reliable activity determinations than by calculation. By modifying the VISE membrane to reduce or prevent protein fouling, even more accurate analytical data should become available.

\section{Acknowledgements}

The authors would like to thank Oxford Biosensors for financial support for this project. We would also like to thank Ian Smith of the John Radcliff Hospital in Oxford for performing blood analysis and Dr Jayani Chandrapala from Monash University for preparing the milk sample.

\section{References}

1 Y. Umezawa, P. Buhlmann, K. Umezawa, K. Tohda and S. Amemiya, Pure Appl. Chem., 2000, 72, 1851-2082.

2 Y. Umezawa, K. Umezawa, P. Buhlmann, N. Hamada, H. Aoki, J. Nakanishi, M. Sato, K. P. Xiao and Y. Nishimura, Pure Appl. Chem., 2002, 74, 923-994. 
3 Y. Umezawa, P. Buhlmann, K. Umezawa and N. Hamada, Pure Appl. Chem., 2002, 74, 995-1099.

4 Q. Ye, Z. Keresztes and G. Horvai, Electroanalysis, 1999, 11, 729-734.

5 M. Sharp, Anal. Chim. Acta, 1976, 85, 17-30.

6 W. J. Albery, P. N. Bartlett and D. H. Craston, J. Electroanal. Chem. Interfacial Electrochem., 1985, 194, 223-235.

7 J. Albery, P. Bartlett, H. Craston, M. Bycroft and P. Jones, Bioelectrochemical Assay and Apparatus, 47pp, EP184909, 1986.

8 M. G. Boutelle, C. Stanford, M. Fillenz, W. J. Albery and P. N. Bartlett, Neurosci. Lett., 1986, 72, 283-288.

9 A. S. N. Murthy, Anita and R. L. Gupta, Anal. Chim. Acta, 1994, 289, 43-46.

10 S. J. Shaw, F. Marken and A. M. Bond, Electroanalysis, 1996, 8, 732-741.

11 A. M. Bond, P. G. Symons and S. Fletcher, Analyst, 1998, 123, 1891-1904.

12 T. J. Wooster, A. M. Bond and M. J. Honeychurch, Anal. Chem., 2003, 75, 586-592.

13 M. Cano, B. Palenzuela and R. Rodríguez-Amaro, Electroanalysis, 2006, 18, 1068-1074.

14 T. J. Wooster and A. M. Bond, Analyst, 2003, 128, 1386-1390.

15 J. Zhang, A. R. Harris, R. W. Cattrall and A. M. Bond, Anal. Chem., 2010, 82, 1624-1633.

16 P. Bonhote, A. P. Dias, N. Papageorgiou, K. Kalyanasundaram and M. Gratzel, Inorg. Chem., 1996, 35, 1168.

17 D. R. MacFarlane, P. Meakin, J. Sun, N. Amini and M. Forsyth, J. Phys. Chem. B, 1999, 103, 4164.

18 A. Harris, J. Zhang, A. Konash, D. Elton, M. Hyland and A. Bond, J. Solid State Electrochem., 2008, 12, 1301-1315.

19 A. M. Bond, S. Fletcher, F. Marken, S. J. Shaw and P. G. Symons, J. Chem. Soc., Faraday Trans., 1996, 92, 39253933.

20 M. F. Suarez, A. M. Bond and R. G. Compton, J. Solid State Electrochem., 1999, 4, 24-33.

21 R. J. Hurditch, V. M. Vincent and J. D. Wright, J. Chem. Soc., Faraday Trans. 1, 1972, 68, 465-477.

22 L. R. Melby, R. J. Harder, W. R. Hertler, W. Mahler, R. E. Benson and W. E. Mochel, J. Am. Chem. Soc., 1962, 84, 3374-3387.

23 F. Wudl, D. Wobschall and E. J. Hufnagel, J. Am. Chem. Soc., 1972, 94, 670-672.

24 M. C. Grossel and S. C. Weston, J. Phys. Org. Chem., 1992, 5, 533-539.

25 Y. Qin and E. Bakker, Anal. Chem., 2002, 74, 3134-3141.

26 R. P. Buck, K. Toth, E. Graf, G. Horvai and E. Pungor, J. Electroanal. Chem. Interfacial Electrochem., 1987, 223, 51-66.
27 Y. Qin, Y. Mi and E. Bakker, Anal. Chim. Acta, 2000, 421, 207220.

28 Ionic Liquids in Synthesis, ed. P. Wasserschied and T. Welton, Wiley-VCH, Weinheim, 2002.

29 J. Dupont, R. F. de Souza and P. A. Z. Suarez, Chem. Rev., 2002, 102, 3667.

30 F. Endres, ChemPhysChem, 2002, 3, 144.

31 J. S. Wilkes, Green Chem., 2002, 4, 73.

32 R. Sheldon, Chem. Commun., 2001, 2399.

33 T. Welton, Chem. Rev., 1999, 99, 2071.

34 W. Kubo, T. Kitamura, K. Hanabusa, Y. Wada and S. Yanagida, Chem. Commun., 2002, 374.

35 A. E. Visser, J. D. Holbery and R. D. Rogers, Chem. Commun., 2001, 2484.

36 S. Chun, S. V. Dzyuba and R. A. Bartsch, Anal. Chem., 2001, $73,3737$.

37 A. E. Visser, R. P. Swatloski, W. M. Reichert, S. T. Griffin and R. D. Rogers, Ind. Eng. Chem. Res., 2000, 39, 3596.

38 A. E. Visser, R. P. Swatloski and R. D. Rogers, Green Chem., 2000, 2, 1.

39 C. D. Liang, C. Y. Yuan, R. J. Warmack, C. E. Barnes and S. Dai, Anal. Chem., 2002, 74, 2172.

40 R. Wang, S. Hoyano and T. Ohsaka, Chem. Lett., 2004, 6.

41 J. Niedziolka, E. Rozniecka, J. Stafiej, J. Sirieix-Plenet, L. Gaillon, D. di Caprio and M. Opallo, Chem. Commun., 2005, 2954.

42 C. Coll, R. H. Labrador, R. M. Manez, J. Soto, F. Sancenon, M.-J. Segui and E. Sanchez, Chem. Commun., 2005, 3033.

43 J. Zhang and A. M. Bond, J. Phys. Chem. B, 2004, 108, 7363.

44 A. I. Bhatt, A. M. Bond, D. R. MacFarlane, J. Zhang, J. L. Scott, C. R. Strauss, P. I. Iotov and S. V. Kalcheva, Green Chem., 2006, 8, 161-171.

45 A. R. Harris, A. Nafady, A. P. O'Mullane and A. M. Bond, Chem. Mater., 2007, 19, 5499-5509.

46 A. J. Bard and L. R. Faulkner, Electrochemical Methods, Wiley, New York, 2001.

47 M. Pakula, A. Swiatkowski, M. Walczyk and S. Biniak, Colloids Surf., A, 2005, 260, 145-155.

48 T. A. DelValls and A. G. Dickson, Deep Sea Res., Part I, 1998, 45, 1541-1554.

49 A. K. Covington and R. Kataky, J. Chem. Soc., Faraday Trans., 1993, 89, 369-376.

50 V. Gavalas, M. Berrocal and L. Bachas, Anal. Bioanal. Chem., 2006, 384, 65-72.

51 R. Luxton, Clinical Biochemistry, Butterworth Heinemann, Oxford, 1999.

52 G. D. Christian, Analytical Chemistry, Wiley, New York, 1977. 